\title{
ANÁLISE QUALITATIVA DE DADOS DE ENTREVISTA: UMA PROPOSTA
}

\author{
Zélia Maria Mendes Biasoli Alves(*) \\ Maria Helena G. F. Dias da Silva(**)
}

\section{RESUMO}

A abordagem qualitativa em pesquisa nas áreas da Educação $\theta$ Ciências Sociais tem representado um caminho alternativo à rigidez positivista. Entretanto, vem preocupando os pesquisadores brasileiros pela sua característica de não sistematização. Face a isso, o presente trabalho visa contribuir para uma discussão metodológica sobre análise qualitativa ao relatar um procedimento sequenciado, sistematizado e passivel de ser aplicado a dados de entrevistá semi-estruturada e livre, que compreende todos os passos, da construção do instrumento para coleta de dados à apreensão do significado das falas dos sujeitos, terminando numa redação precisa, dentro do enfoque teórico do pesquisador.

A análise qualitativa de dados é um fenômeno recentemente retomado, que se caracteriza por ser um processo indutivo que tem como foco a fidelidade ao universo de vida cotidiano dos sujeitos, estando baseada nos mesmos pressupostos da chamada pesquisa qualitativa. ${ }^{1}$

Segundo André (1983) ela visa apreender o caráter multidimensional dos fenômenos em sua manifestação natural, bem como captar os diferentes significados de uma experiência vivida, auxiliando a compreensão do indivíduo no seu contexto.

Atualmente vem-se discutindo muito a necessidade de requisitos básicos para levar a efeito uma análise qualitativa, e a maioria dos autores ligados ao tema considera que a experiência do pesquisador - dentro da área, com a literatura pertinente e diferentes formas de analisar dados de entrevista - seja uma condiçāo "sine qua non" para que realize um estudo adequado, levando-se em copta que ele (pesquisador) $\epsilon$, na realidade, o seu próprio instrumento de trabalho (Joly Gouveia, 1984). *

(') Professora Assistente Doutora do Departamento de Psicologia e Educaçăo da Fac. Fil., Ciéncias c Latres de Ribeirbo Preto - USP.

(*) Professora Assistente do Departamento de Didática da UNESP de Araraquara.

1. Ao mesmo tempo ela se distingue de abordagens jornalísticas, amadoras ou de leituras pessoais imediatistas e subjetivas dos relatos orais.

Paidéia, FFCLRP - USP, Rib. Preto, 2, Fev/Jul, 1992. 
Porém, há uma difículdade imediata: a não existência de procedimentos apropriados devidamente descritos na literatura (Ludke \& André, 1986), o que torna o pesquisador inseguro na delimitação de critérios e passos metodológicos.

Aparecem então, com frequência, dúvidas como a levantada por Campos (1984) que diz existir uma questão nem sempre resolvida que é a de garantia de que o trabalho se constitua realmente em pesquisa, ou seja, conhecimento crítico da realidade, e não simples exercício de camaradagem ou ativismo; e, a literatura brasileira a respeito é escassa.

Assim, se por um lado as abordagens qualitativas apontam caminhos alternativos - à rigidez positivista - para os pesquisadores em Educaçāo, Ciências Sociais e Humanas, por outro lado, elas vêm gerando preocupação entre cientistas brasileiros pela sua característica de não sistematização (Ludke \& André 1986; Trivinos, 1987; Nicolaci da Costa, 1988).

E importante salientar que, ainda que os passos metodológicos numa abordagem qualitativa não estejam prescritivamente propostos, 0 pesquisador não deve se considerar um sujeito isolado que se norteia apenas pela sua intuição: há que levar em conta o contato com a realidade pesquisada, associado aos pressupostos teóricos que sustentam seu projeto. Assim, ao fugir da rigidez o pesquisador não deverá perder o rigor em seu trabalho - regra primeira para a concretização de um projeto científico que possa vir a contribuir para um conhecimento na área (Gomes, 1990).

Há trabalhos recentes que vêm estabelecendo pontos a serem considerados e alguns critérios para se levar a efeito uma análise qualitativa. André (1983) propôs uma modalidade que chamou "Análise de Prosa" definida como sendo "uma forma de investigação do significado dos dados qualitativos onde tópicos e temas vão sendo gerados a partir do exame dos dados e sua contextualização no estudo, sendo preciso que estes tópicos e temas sejam freqüentemente vistos, questionados e reformulados, na medida em que a análise se desenvolve, tendo em vista os princípios teóricos e os pressupostos da investigação" (p.57).

Forghieri (1990) discute também a problemática de se levar a efeito pesquisa qualitativa dentro da abordagem fenomenológica e apresenta os procedimentos de pesquisa que vem utilizando e que compreendem uma seqüência de etapas. Na mesma linha há o trabalho de Mansini (1989) que define o método fenomenológico como o conjunto de regras formais necessárias ao desenvolvimento de uma atitude para compreender o que se mostra.

Ao investigar práticas educativas na familia através de entrevistas com mães, Biasoli Alves e Graminha (1984); Biasoli Alves, Graminha e Caldana (1985) e Dias da Silva (1986) detectaram a necessidade de levar a efeito uma forma de análise de dados - posteriormente a tê-los trabalhado quantitativa e 
isoladamente - que desse conta da riqueza da fala das mães, e ao mesmo tempo as contextualizasse.

Trabalhos de aprofundamento gradativo foram estabelecendo análises que indúram primeiro aspectos e depois significados e dimensōes (Biasoli Alves e Caldana, 1986; Biasoli Alves, Dias da Silva, Sigolo e Caldana, 1987). A conseqüência desses estudos foi gerar, de forma indutiva, um sistema que (adequado aos objetivos dos projetos em questão) aborda o discurso do sujeito de forma qualitativa, e permite ampliaçōes e adaptaçōes para trabalhos de outros pesquisadores.

Assim, este relato visa, a partir da descrição e exemplificação dos procedimentos levados a efeito, dar elementos para uma discussão metodológica sobre como estruturar sistemas para analisar qualitativamente dados de entrevista.

centrais.

A partir dessa experiência datada foram definidos três tópicos

\section{I - A necessidade de obter dados dentro de um contexto.}

Estudos metodológicos vêm afirmando que o formato da entrevista, bem como o tipo de egistro observacional, determinam de maneira muito estreita a análise de dados que é possível e adequado fazer (Newson \& Newson, 1976; Biasoli Alves e Marturano, 1987). Portanto, ao pretender realizar uma analise qualitativa seria fundamental verificar como deveria ocorrer a coleta de dados, mais especificamente, que formato de entrevista seria o mais pertinente (Biasoli Alves, Dias da Silva, Sigolo e Caldana, 1987). E, os estudos encaminham preferentemente para propostas de entrevistas definidas por Cannel e Kahn (1974) como semi-estruturadas, que pedem uma composição de roteiro com tópicos gerais selecionados e elaborados de tal forma a serem abordados com todos os entrevistados.

Trata-se de definir nucleos de interesse do pesquisador, que têm vinculação direta aos seus pressupostos teóricos (abordagem conceitual) e contatos previos com a realidade sob estudo; ou seja, existe uma direçảo, ainda que não de forma totalmente declarada, para o contelado que vai ser obtido nas entrevistas (Queiroz, 1987), ao mesmo tempo em que a garantia de adequação do roteiro ao universo de vida dos sujeitos.

2. Diree-in entilo que os objetivos estajo em: 12 Pornecer uma descriçlo de um procedimento que permitiu a apreensto de dados relevantes e válidos nas respostas de míes a um roteiro cemleetruturado de entrevista que focalizava sua maneira de criar e educar filhos. 20 Discutir a caricterizaça e sequenciagato de passos pelo pesquisador, feita a posteriori, atraves da identificaçăo das tarefas especficicas a serem desempenhadas e suas especificaçoes. 
Esse formato pede também uma formulação flexivel das questōes, cuja seqüência e minuciosidade ficarāo por conta do discurso dos sujeitos e da dinâmica que flui naturalmente no momento em que entrevistador e entrevistado se defrontam e partilham uma conversa permeada de perguntas abertas, destinadas a "evocar ou suscitar" uma verbalização que expresse o modo de pensar ou de agir das pessoas face aos temas focalizados, surgindo então a oportunidade de investigar crenças, sentimentos, valores, razöes e motivos que se fazem acompanhar de fatos e comportamentos, numa captação, na íntegra, da fala dos sujeitos ${ }^{3}$.

Mas, para chegar à realizaçāo das entrevistas, há vinculado com esse primeiro tópico, mais um conjunto de aspectos qualitativos, que os pesquisadores que fazem uso dessa abordagem vêm salientando.

Fernandes (1991), ao discutir o trabalhar com relato oral, afirma que ao realizar uma entrevista o pesquisador estabelece uma relação com os pesquisados, e referindo-se às reflexōes propostas por François Luberherr ligadas às dimensōes humanas na utilização desta técnica, diz que "... longe de se constituir em tarefa atribuída a debutantes, ela concretiza o lugar privilegiado onde se articulam conhecimento livresco e realidade espontânea, princípios universais e o singular concreto, conceptualização formalista e intuição pessoal. E, sobretudo obriga o pesquisador a se interrogar sobre si próprio e suas motivações para poder questionar os outros" (p.10).

Assim é que das atitudes de aproximação, respeito e empatia trazidas pelo pesquisador; vira a disponibilidade dos sujeitos e o seu envolvimento com a tarefa de informantes (o que amplia a possibilidade de validade dos dados obtidos), fazendo dela um momento de reflexão, retomada de fatos, valores e idéias do passado (quando este é o caso) e a gratificação com sua transmissāo ao entrevistador.

A parte o lado humano, esse tipo de coleta de dados coloca a necessidade de o pesquisador fazer o que Mettel (1988) define como sendo o "bom uso da tecnologia" e que significa nesse caso lançar mão do recurso "gravação" para poder ao mesmo tempo auferir a vantagem da maior preservação possível do discurso dos entrevistados, e evitar o seu comprometimento, bem como da própria interação, pela tarefa de tomar nota das respostas.

Queiroz (1987) discute, pormenorizadamente, os problemas e cuidados que, apesar da gravação, precisam ser levados em conta, e que vão implicar no trabalho custoso e lento de uma transcrição literal, de preferência

3. A composiçăo de um roteiro com questóes abertas, sem a delimitaçăo de respostas atraves de perguntas fechadas ou do tipo diferencial semántico, já proporciona um dado que se adequa à andise qualitativa; isto equivale a dizer que, por outro lado, roteiros altamente estruturados e de questós fechadas truncam o discurso do sujeito e ainda que permitindo, ds vezes, uma análise guantitativo-interpretativa, a tornam dificil e podem mesmo envieza-la.

4. Contrariamente a se sentirem explorados $\mathrm{e}$ invadidos.

Paidéia, FFCLRP - USP, Rib. Preto, 2, Fev/Jul, 1992. 
pelo próprio pesquisador; tudo isso exige ainda uma complementação na forma de registros a posteriori, de atitudes do sujeito ou detalhes importantes da situaçáo nảo captados pelo gravador.

Doumanis (1983) reforça, mais uma vez, esses aspectos ligados pessoa que entra em cóntatos com as famflias, faz as coletas de dados, anotações das observaçōes, salientando que devia ser o próprio pesquisador ${ }^{6}$, porque individuos diferentes vão, sem dúvida, gerar atitudes diversas nos sujeitos, principalmente na disponibilidade para responder a questōes sobre si mesmos e sua visão de mundo.

\section{II - Da imensidão à sistematização dos dados.}

A análise qualitativa se caracteriza por buscar uma apreensão de significados na fala dos sujeitos, interligada ao contexto em que eles se inserem e delimitada pela abordagem conceitual (teoria) do pesquisador, trazendo à tona, na redação, uma sistematização baseada na qualidade, mesmo porque um trabalho desta natureza não tem a pretensão de atingir o limiar da representatividade (Fernandes, 1991).

São fatos inquestionáveis que as entrevistas semi-estruturadas, em que o discurso dos sujeitos foi gravado e transcrito na íntegra, produzem um volume imenso de dados que se acham extremamente diversificados pelas peculiaridades da verbalização de cada um.

Assim, para iniciar o trabalho nessa etapa o pesquisador se vê pressionado a retomar seus pressupostos, e três são suas guias mestras: 1 - As questōes advindas do seu problema de pesquisa (o que ele indaga, o que quer saber); 2 - As formulaçōes da abordagem conceitual que adota (gerando pólos especificos de interesse e interpretações possíveis para os dados); 3 - A própria realidade sob estudo (que exige um "espaço" para mostrar suas evidências e consistências).

O momento de sistematização é pois um movimento constante, em váriaś direçōes: das questōes para a realidade, desta para a abordagem conceitual, da literatura para os dados, se repetindo e entrecruzando até que a análise atinja pontos de "desenho significativo de um quadro", multifacetado sim, mas passível de visōes compreensíveis.

Depois de trabalhar com um modelo qualitativo de análise é possível identificar alguns passos - como se fora um esquema - e cuidados contidos dentro desse momento de sistematização.

5. Mas, ainda assim há que preservar as fitas para que se possa recorrer a elas caso necessário.

6. Talvez esse nło seja um grande entrave, uma vez que a abordagem qualitativa define que a análise sera em profundidade mas circunscrita a poucos sujeitos (podendo até ser um so, como no Estudo de caso).

Paidéia, FFCLRP - USP, Rib. Preto, 2, Fev/Jul, 1992. 
a) Há que se falar primeiro da necessidade que o pesquisador assume $^{7}$ de se deixar "impregar" pelos dados, o que vai acontecendo à medida em que ele faz "leituras" da fala dos sujeitos ao longo da entrevista, detendo-se ora numa análise mais imediata do conteudo expresso, ora nas teias de relaçōes que se evidenciam (entre diferentes pontos do discurso, entre ele e a abordagem, entre diferentes concepções do mesmo tema, e assim por diante).

b) Cuidadosamente toda essa leitura e o que dela advém pede anotações (para que nada se "perca"), incluindo as relaçōes feitas, as interpretaçōes levantadas, os pontos críticos identificados e seu significado naquele tópico e na pesquisa como um todo.

c) Paralelamente existe tamberm uma necessidade de "partilha dos dados" com outros pesquisadores, o que se constitui ao mesmo tempo num enriquecimento e numa "checagem" das formas de compreender, explicar e interpretar a massa de informaçōes trazida pela verbalização dos sujeitos. Este procedimento conduz a maior objetividade e precisäo na análise?

d) A literatura sobre o tema é a outra âncora do pesquisador nesse momento, que dela pode extrair comentários, observaçōes que aperfeiçoem (pela melhor definição) os tópicos que investiga; trata-se de um exercício no estabelecimento de relações entre: 1 - o conterdo expresso no conjunto das falas dos sujeitos; 2 - a experiência do pesquisador e sua percepção no entrar em contato com eles e suas informaçōes; 3 - o pensamento registrado (não importa se muito recente ou não, mas em especial vinculado a) pelos que trabalharam (e trabalham) com o mesmo assunto ( ou com aqueles que são afins).

E exatamente porque pesquisar através de uma análise qualitativa quer dizer estar "apreendendo" o fenômeno dentro de todo o seu contexto ${ }^{10} \mathrm{e}$ interpretando seu significado, que esses dois contatos - literatura e outros pesquisadores - são tão importantes e procurados com frequência porque através deles o estudo se insere, de fato, na área, e se "atualiza" com as idéias e o pensamento do passado e do presente.

e) Muitas vezes a "impregnação pelos dados" traz como conseqüência uma quantificação implícita que pode se traduzir na busca de regularidades e diferenças nas respostas que terão nuances de muito interessè: há respostas distintas com um mesmo fundamento, respostas iguais com fundamentos diferentes e mesmo algumas contraditórias em um único sujeito, e por fim as exceçōes.

7. Essa necessidade vem de tres vertentes: a) o pesquisador "quer" entrar em contato com a realidade e "desvendá-la"; b) ele precisa fazer isso porque sabe que é o único caminho possível para que seu trabalho se aprofunde e se expanda; c) a "realidade" vem de encontro a cle, por si só o atrai.

8. Preferentemente envolvidos com temas afins, e com experiencia na área.

9. A presenga de pontos de vista diversos sobre o que os "dados falam" será sempre benefica para a pesquisa qualitativa, gerando instanctas de aparecimento de novas perguntas e inferencias.

10. Sócio-histórico-cultural-psicológico.

Paidéia, FFCLRP - USP, Rib. Preto, 2, Fev/Jul, 1992. 
D Gradativamente a análise vai acontecendo e o pesquisador passa a trabalhar num aprofundamento dos dados que ficarão contidos numa estrutura, guiada pelo tema e questōes centrais. Há quem chame a esse processo de afunilamento tendo em vista a seleção entre tópicos pela sua maior ou menor abrangência e importância para a pesquisa.

\section{III - A composiçåo dos resultados pela redaçăo.}

Redigir significa, na análise qualitativa, a sua concretização: há a eleição de tópicos e temas, uma seqüência de narrativa ancorada na literatura e nas próprias verbalizaçōes dos sujeitos ${ }^{11}$, em que o cuidado com a linguagem fica por conta de elaborar uma redaçâo coerente e fluida que encaminhe o leitor para a compreensão, análise e crítica do texto (Aries, 1973).

Existem certos recursos à disposição do pesquisador, mas eles vêm mesclados a certas normas implícitas. Primeiro, pode-se e deve-se usar da literatura e, em especial, da fala dos sujeitos como parte da redação, das explicitaçōes e interpretaçōes, mas o dado precisa estar acima de tudo e muito saliente; segundo, o pesquisador trança informaçöes diversas, recorre ao conhecimento em áreas afins, e busca um significado para elas, mas não lhe é permitido compactuar com o "achismo"; terceiro, ele trabalha artesanalmente "pintando" um quadro mas que deverá ser fiel e vinculado ao problema de pesquisa que investiga, ou seja, a sua "criação" está contida e delimitada pela realidade expressa pelos sujeitos (Biasoli-Alves \& Dias da Silva, 1987).

\section{Pontos e contrapontos}

Esse relato vem com o objetivo de propor, num sentido amplo, procedimentos para levar a efeito análises qualitativas de dados de entrevista, de tal modo a suscitar discussōes, novas aplicaçōes e redefiniçōes, que possam fazer progredir esse modelo de trabalho na área da psicologia ${ }^{12}$.

Cumpre apenas enfatizar que se a preocupação metodologica do pesquisador ao trabalhar com análise qualitativa reside em uma apreensão abrangente do fenômeno estudado, aliada à garantia de estar passando um conhecimento crítico da realidade, ele necessita, para cumprir seus objetivos, de muito tempo, disponibilidade, conhecimento e experiência na área e muita, mas muita seriedade no seu trabalho.

11. O relatar dados aparece com caracteristicas muito diversas das que se observa ao trabalhar quantitativamente, em que tabelas e gráficos falam por si sbs e as palavras assumem a conotaçato centa das definiçós operacionais e compoem uma comunicaça de pesquisa empírica no modelo positivista.

12. Dir-e-ia: apenas um estímulo inicial. 


\section{REFERENCIAS}

ANDRE, M. E. D. A. (1983). Texto, contexto e significado: algumas questōes na análise de dados qualitativos. Cadernos de Pesquisa, (45): 66-71.

ARIES, P. (1973). L'enfant et la vie familiale sous l'ancien régime.Éditions du Seuil, Paris.

BIASOLI-ALVES, Z. M. M. \& MARTURANO, E. M. (1977). Problemas e soluçōes de Metodologia Observacional no estudo da interação Mãe-Criança. Texto impresso, FFCLRP-USP.

BIASOLI-ALVES, Z. M. M. \& MARTURANO, E. M. (1971). Questões metodológicas no estudo da interação humana. Anais da 17• Reunião Anual de Psicologia, SPRP, Ribeiräo Preto, p. 531-541.

BIASOLI-ALVES, Z. M. M. \& GRAMINHA, S. S. V. (1984) Motives underlyng the child-rearing practice used by urban families of middle and middle-high socioeconomic-cultural level. Annual Research Report, (1):60-61

BIASOLI-ALVES, Z. M. M.; GRAMINHA, S. S. V. \& CALDANA, R. H. L. (1985). Children's problems and educational practice by different samples of mothers. Annual Research Report, (2): 31-32.

BIASOLI-ALVES, Z. M. M. \& CALDANA, R. H. L. (1986). Demands and authority. Evaluation of the ideal. Annual Research Report, (3):17.

BIASOLI-ALVES, Z. M. M. \& DIAS DA SILVA, M. H. G. F. (1987) Some changes in childrearing practices. Annual Research Report, (4):64-70.

BIASOLI-ALVES, Z. M. M.; DIAS DA SILVA, M. H. G. F.; SIGOLO, S. R. R. L. \& CALDANA, R. H. L. (1987). Childrearing practices: a methodology for the analysis of interview data. Annual Research Report, (4):53-63.

CANNEL, C. F. \& KAHN, R. L. (1974). Coleta de dados por entrevista. In: FESTINGER, L. \& KATZ, D. A pesquisa da psicologia social. Rio de Janeiro, EFGV.

CAMPOS, M. M. (1984). Pesquisa participante: possibilidades para o estudo da escola. Cadernos de Pesquisa, (19):63-66.

DIAS DA SILVA, M. H. G. F. (1986). A educaçåo dos filhos pequenos nos ultimos 50 anos: uma busca do "melhor"? Dissertação de Mestrado. Instituto de Psicologia/Universidade de São Paulo, São Paulo, 1988.

DOUMANIS, M. (1983). Mothering in Greece: from collectivism to individualism. New York, Academic Press. 
FERNANDES, M. E. (1991. Memória Camponesa. Anais da 21• Reunião Anual de Psicologia, SPRP, Ribeirão Preto, 20 pags. (no prelo).

FORGHIERI, Y. C. (1990). O método fenomenológico na pesquisa psicológica. Anais do $3^{2}$ Simpósio de Pesquisa e Intercâmbio Cientínco, ANPEPP. Águas de São Pedro, São Paulo, 244-248.

GOMES, W. (1990). Consideraçōes sobre a submissão de projetos que utilizam métodos qualitativos de pesquisa para agências financeiras. Anais do $3{ }^{\circ}$ Simpósio de Pesquisa e Intercâmbio Cientínco, ANPEPP. Águas de São Pedro, São Paulo, 239-243.

JOLY GOUVEIA, A. (1984). Notas a respeito das diferentes propostas metodologicas apresentadas. Cadernos de Pesquisa, (49): 67-70.

LUDKE, M. \& ANDRE, M. E. D. A. (1986). Pesquisa em Educação: abordagens qualitativas. São Paulo, EPU.

MANSINI, E. (1989). Enfoque fenomenológico de pesquisa em educação. In: FAZENDA, I. (Org.). Metodologia da Pesquisa Educacional. São Paulo, Cortez.

METTEL, T. P. L. (1988) Reflexões sobre a metodologia observacional de enfoque etologico aplicada em pesquisas com excepcionais. Anais da 180 Reuniāo Anual de Psicologia, SPRP, Ribeirão Preto, 253-256.

NICOLACI-DA-COSTA, A. M. (1988). Análise do discurso e pesquisa qualitativa. Anais da 18` Reunião Anual de Psicologia, SPRP, Ribeirão Preto, 501-504.

NEWSON, G. \& NEWSON, E. (1976). Four years old in a urban community. Penguin Books, London.

QUEIROZ, M. I. P. (1987). Relatos orais: do "indizivel" ao "dizível". Ciência e Cultura, São Paulo, 39(3):272-286.

TRIVINOS, A. N. S. (1987). Introdução à pesquisa em Ciências Sociais: a pesquisa qualitativa em educação. São Paulo, Atlas.

\section{ABSTRACT}

The qualitative approach in educational and social sciences research has presented an alternative woy to positivism rigidity. However, its lack of sistematization worries Brazilian researchers. Than, ths paper is devoted to a methodological discussion about qualitative analysis through the account of ene aquence of procedures, applicable to interview data (guide free and part structured). The gatem comprisses some degress from the data collection to the subjects speech aprehension of meaning and adds a precise report, respected the researcher theoretical approach. 